\title{
Capital, desigualdade e o passado que devora o futuro
}

PIKETTY, THOMAS (2014). O capital no século XXI, Lisboa: Temas e Debates - Círculo de Leitores, 910 pp. ISBN 9789896443047

O capital no século XXI é daquelas obras a que poucos ficarão indiferentes. Assente na tentativa de aproximação da economia a outras ciências sociais, sobretudo à história, e numa virtuosa simplicidade conceptual, traça em mais de 900 páginas a evolução do ordenamento da riqueza nos últimos dois a três séculos, quer entre diferentes países quer no seio de um mesmo país. Este último âmbito de distribuição do capital ${ }^{1}$ e do fluxo de rendimento proporcionado por este mesmo capital e/ou pelo exercício de uma determinada atividade suscita de forma particular o interesse de Piketty (2014), pois a desigualdade no presente, como ele próprio reconhece, “[...] opõe muito mais os ricos e os pobres de cada país do que os países entre si" (p. 77). Os grandes propósitos orientadores da sua análise passam, fundamentalmente, por mostrar os grandes princípios que sustentam a acumulação elitista de capital, as profundas desigualdades daí resultantes e a necessidade política de implantação de um sistema abrangente de tributação fiscal progressiva do patrimônio. Embora o capital conste como a grande referência no título

\footnotetext{
* Doutorado em Antropologia; professor auxiliar no Departamento de Economia, Sociologia e Gestão da Universidade de Trás-osMontes e Alto Douro (DESG-UTAD, Portugal); investigador efectivo do Centro de Estudos Transdisciplinares para o Desenvolvimento (CETRAD-UTAD), entidade financiada por fundos nacionais através da Fundação para a Ciência e a Tecnologia (FCT), no âmbito do projecto UID/SOC/O4O11/2013. Correio eletrônico: octavsac@utad.pt

1. Entendido pelo autor como stock de patrimônio financeiro, imobiliário, fundiário, industrial ou outro passível de transação mercantil.
} 
do livro, a discussão direciona-se mais para os desequilíbrios na distribuição da riqueza do que propriamente para as estruturas e os processos sociais que a constituem.

Este trabalho revela-se verdadeiramente impressionante, tendo em conta a significativa transversalidade histórica e geográfica e a sua dimensão comparativa. Abarca séries estatísticas desde os séculos XVIII, XIX e XX até a primeira década do século XXI e considera mais de duas dezenas dos países economicamente mais influentes ${ }^{2}$, o que, a espaços, tende a conferir uma feição labiríntica à análise. Para tal empreendimento, o autor beneficiou-se de uma vasta rede de colaborações e usou uma grande diversidade de fontes históricas. No que diz respeito a estas últimas, além de informações relativas à produção de riqueza à escala nacional e aos patrimônios dos vários países considerados, prestou especial atenção a elementos que permitem situar a análise no plano individual. Considerou, entre outras bases documentais, as declarações individuais de rendimentos, implementadas em muitos países no início do século XX, e as declarações sucessórias, que remontam à primeira metade do século XIX. As primeiras proporcionam dados sobre o modo como, historicamente, vêm sendo distribuídos os rendimentos do trabalho e do capital; as segundas sobre a transmissão patrimonial entre gerações e as assimetrias de capital que aí vão ganhando forma. É delineado, deste modo, um balanço integrado que nos mostra com notável detalhe empírico os contornos da localização social da riqueza. A partir daqui são projetados cenários futuros de evolução das desigualdades.

No seu posicionamento teórico, Piketty (2014) não partilha propriamente a visão catastrófica que Ricardo e Marx formularam no século XIX sobre as fortes desigualdades de capital então existentes. Ao mesmo tempo, manifesta um distanciamento ainda maior face ao encantado optimismo expresso por Simon Kuznets 3 na sua famosa "curva" em forma de sino, segundo a qual as desigualdades tenderiam a aumentar num primeiro estádio da industrialização e do crescimento econômico e, numa fase posterior, com a ampliação desse mesmo crescimento, a estabilizar e depois a decrescer de forma bastante significativa. Os dados históricos reunidos no livro mostram que os contrastes de rendimento e, sobretudo, de patrimônio eram bastante pronunciados na generalidade dos países desenvolvidos até às vésperas da I Guerra Mundial, ${ }^{4}$ atenuando-se bastante desde aí até por volta dos anos de 1970. Este esbatimento das desigualdades não foi, todavia, resultado da pujança econômica ou de qualquer outro determinismo econômico, como suporia Kuznets. Foi antes uma consequência da devastação decorrente das duas

2. A ele está associada uma base de dados mundial em construção - The world top incomes database (http://topincomes. parisschoolofeconomics.eu/) -, bem como anexos técnicos (http://piketty.pse.ens. fr/fr/capital21c), que poderão ser consultados para aceder a elementos mais detalhados e complementares.

3. Prémio Nobel da economia em 1971.

4. A França e a Inglaterra, muito mais que os EUA, são exemplos paradigmáticos destas fortíssimas clivagens nas "sociedades patrimoniais” dos séculos XVIII e XIX. Piketty faz, aliás, interessantes incursões nos enredos dos romances de Balzac e de Jane Austen para tentar ilustrar sociologicamente as evidências estatísticas que nos vai apresentando. 
guerras mundiais e das políticas públicas então adoptadas. Com a gradual recuperação econômica após a II Guerra e com as orientações políticas fiscais e financeiras mais favoráveis ao capital, em especial a partir dos anos de 1980, a acumulação patrimonial privada não tem parado de aumentar, produzindo disparidades sociais que, não sendo tão vincadas como as do início do século XX, não deixam de ser preocupantes.

A anatomia social das desigualdades é esboçada por Piketty (2014) em clara ruptura com instrumentos até agora objeto de grande reconhecimento e utilização científica e política, como é o caso do índice de Gini, um indicador sintético que agrega, de modo abstrato e pouco inteligível, diferentes manifestações e dimensões da desigualdade. Em alternativa, desenvolve uma análise baseada em quadros de distribuição da riqueza que, sob a forma de decis e de centis, indicam a parte relativa dos diferentes grupos no total dos rendimentos do trabalho, no total dos patrimônios e no total global dos rendimentos do trabalho e do patrimônio. A partir daqui, e com uma finalidade meramente ilustrativa, estabelece uma tipologia na qual distingue as "classes superiores" como os 10\% mais afluentes 5 , as "classes médias" como os $40 \%$ que se seguem e, por fim, as "classes populares" como os 50\% mais pobres. Tomando como exemplo a Europa em 2010, o total dos rendimentos (capital e trabalho) distribuiu-se por estas diferentes classes da seguinte forma: os 10\% mais ricos auferiram $35 \%$ dos rendimentos globais (10\% para o centil superior e $25 \%$ para os restantes $9 \%$ ), os $40 \%$ seguintes $40 \%$, e os $50 \%$ mais pobres $25 \%$. Temos aqui uma situação de "desigualdade média”, ainda bastante aquém da "desigualdade forte", por exemplo dos EUA, em que os 10\% mais prósperos ficaram na posse de $50 \%$ do valor total de rendimento (20\% para o centil superior e $30 \%$ para os demais 9\%), os 40\% das "classes médias" de 30\% e os 50\% mais pobres somente de $20 \%$ (idem). Ainda que muito sumária, a apresentação destes dois exemplos com base na abordagem de Piketty mostra-nos uma perspectiva das assimetrias mais expressiva e realista que a que obteríamos considerando um índice de Gini de o,36 para a Europa e de o,49 para os EUA.

Ao debater a mecânica da produção das desigualdades, Piketty (2014) identifica “forças de divergência", ou seja, fatores responsáveis por formas muito assimétricas de distribuição e reprodução do capital. A força primordial expressa-a através da fórmula $\mathrm{r}>\mathrm{g}$, sendo que $r$ (capital return) indica a taxa de rentabilidade anual do patrimônio privado e $g$ (economic growth) a taxa de crescimento do rendimento e da produção. Sempre que $r$ é bastante maior que $g$ - uma tendência histórica apenas atenuada em alguns períodos do século XX e que tem vindo a instalar-se no presente século - o stock patrimonial que vem do passado proporciona um fluxo de rendimento incomparável, aumenta exponencialmente e sobrepõe-se à progressão do patrimônio resultante do trabalho, gerando uma espiral de concentração de riqueza e desigualdade que se acen-

5. Dentro desta categoria distingue ainda os $1 \%$ mais ricos como "classes dominantes" e os restantes $9 \%$ como "classes desafogadas". 
tuará no tempo. Segundo Piketty (2014), a rentabilidade média anual contemporânea do capital, em torno de $4 \%$ a $5 \%$, por relação com taxas de crescimento da economia na ordem de $1 \%$ a $1,5 \%{ }^{6}$ deixa perceber que o valor do capital multiplica-se a um ritmo muito superior ao do valor do trabalho.7 Daqui resulta que os herdeiros de fortunas não precisarão de muito esforço ou mérito para alcançar posições de prosperidade e de distinção social que, dificilmente, alguém conseguirá somente pelo seu esforço, empreendedorismo e/ou competência. Estamos a presenciar, já desde as últimas décadas do século passado, o regresso gradual da força da inércia da riqueza acumulada, como poderemos constatar, por exemplo, com o aumento dos fluxos sucessórios e do peso relativo da herança no total dos recursos.

Embora as projeções de longo prazo feitas por Piketty possam ser questionáveis e até enredar-se em determinismos econômicos de que ele próprio afirma querer fugir, não é de todo impertinente admitir a possibilidade de estarmos a entrar num tempo em que o "passado devora o futuro", para utilizar a sua feliz expressão. Um tempo em que a meritocracia poderá transformar-se em ilusão e a democracia deixar de ter substrato para ser, de facto, concretizada. Enfim, um tempo a fazer lembrar, com as devidas distâncias, as sociedades rentistas de herdeiros ociosos de há dois ou três séculos. Aliás, na sua totalidade, os patrimônios privados, depois da forte delapidação provocada pela Grande Depressão e pelas duas guerras mundiais, evidenciam hoje em dia uma prosperidade semelhante à da Belle Époque. Porém, há uma grande diferença. Ao contrário de outrora, existe na atualidade um amplo estrato socioeconômico, que o autor designa por "classe média patrimonial", do qual faz parte, aproximadamente, metade da população, possuindo no seu conjunto cerca de $1 / 3 \mathrm{a}^{1} / 4$ do patrimônio nacional. É graças a esta relevante transformação estrutural que a atual aglomeração do capital não atinge os níveis verdadeiramente astronômicos de há pouco mais de um século. Apesar de tudo, continua bastante elevada e claramente injustificada, provocando clivagens atentatórias da equidade e da cidadania, e em nada contribuindo para a dinamização da economia, a criação de postos de trabalho e a urgente revitalização do já centenário Estado Social.

Perante um cenário de concentração patrimonial com tantos efeitos perversos, e que poderá continuar a agravar-se, como mudar o rumo? Contrariando qualquer forma de naturalização da desigualdade e as perspectivas que a concebem como resultado inevitável de determinismos econômicos, Piketty (2014) coloca a discussão no campo da

6. À exceção de países emergentes como os BRICS.

7. Compreende-se, assim, que as desigualdades decorrentes da maior ou menor posse de capital sejam quase sempre mais fortes que as desigualdades associadas ao trabalho e aos salários. Contudo, não podemos com isto negligenciar o facto de as significativas hierarquias salariais - muito em especial nos países anglo-saxônicos (v.g. EUA), desde os início dos super-salários dos altos-quadros e de uma fiscalidade favorável nas décadas de 1970-1980 - representarem também uma importante "força de divergência”, contribuindo para a instauração de fortes assimetrias. 
política e das possibilidades democráticas de manter o status quo ou de alterar o modo como os coletivos, os diferentes Estados, se posicionam perante a (re)distribuição da riqueza. Tratando-se de uma questão de escolha política, um imposto progressivo anual sobre o capital seria, no seu entender, a mais justa e eficaz "força de convergência" para controlar a acumulação exacerbada do patrimônio. Esta proposta consiste num sistema de tributação anual, incidindo somente sobre o patrimônio total individual (não sobre os rendimentos) e estruturado segundo uma tabela com taxas progressivas em função do valor desse mesmo patrimônio. Num dos vários cenários apresentados no livro, os valores patrimoniais globais inferiores a um milhão de euros ficariam isentos (ou pagariam uma taxa muito residual), entre um e cinco milhões seriam tributados a $1 \%$ ao ano, mais de cinco milhões a $2 \%$ e, no caso de se optar por uma maior incidência sobre as mega fortunas, seriam destinadas taxas entre $5 \%$ a $10 \%$ para valores superiores a mil milhões de euros.

Para ser bem sucedido, tal imposto pressupõe, entre outras condições, a realização de cadastros integrados de todos os bens privados e uma extensa e estreita concertação internacional, de modo a que a escala da sua aplicação seja suficientemente ampla para evitar paraísos fiscais a drenar capital dos países onde deveria ser sujeito a tributação. Esta condição de largo consenso político, por exemplo em blocos continentais como a Europa, é apontada por muitos como uma utopia e é mesmo um dos principais focos de crítica ao livro de Piketty. Ele próprio facilita e dá algumas munições. É o primeiro a acentuar o registo utópico da sua proposta, não procurando defender a ideia de que as grandes mudanças estruturais começam quase sempre como utopia, nem tampouco mostrar convincentemente que, além do mais, já existem experiências históricas de ampla articulação política transnacional, como é o caso da Organização das Nações Unidas e da União Europeia, cuja construção implicou derrubar obstáculos até então impensáveis de ultrapassar.

Alguns dos que olham com cepticismo para a capacidade dos diferentes Estados convergirem na criação de um regime fiscal para a riqueza apresentam propostas alternativas de combate à desigualdade. No entender de Galbraith (2014), a par de uma tributação mais pesada sobre os lucros das grandes empresas e os dividendos, o aumento do salário mínimo seria uma medida bastante eficaz para baixar o retorno do capital, gerado à custa de baixos salários, e de combater desequilíbrios injustificados de patrimônio e de renda. Trata-se de uma medida plausível. Importa, todavia, ter em consideração que a proposta de Piketty poderá comportar muitos outros efeitos profundamente benignos além do combate às desigualdades. Dentre eles, a produção de conhecimento sobre as fortunas e consequente acréscimo de transparência num contexto em que são muitas as mãos invisíveis que intervêm a bel-prazer nos mercados - como ficou provado com a crise financeira global de 2008 - e uma alternativa ao austeritarismo enquanto estratégia de gestão das dívidas públicas que estrangulam o futuro de muitos 
países. Enfim, representaria uma forma de a democracia ganhar efetivo controle sobre os desmandos do capitalismo e um importante contributo para a promoção das funções sociais do Estado, desde logo na educação e na formação, áreas de enorme influência na redução das desigualdades.

Considerada por muitos como irrealizável, a ideia de sujeição do patrimônio a um sistema de coleta global é censurada pela direita e apreciada com alguma ambiguidade pela esquerda, apontando-a como positiva, mas insuficiente, algo ingênua e pouco consequente no debate sobre o capitalismo. Aliás, não só esta proposta, como o livro de Piketty no seu todo, apesar dos elogios de economistas tidos como "de esquerda" (v.g. Krugman, Roubini), parece ser acolhido com pouco entusiasmo por muitos dos que procuram novas coordenadas para questionar os fundamentos das estruturas capitalistas. Entende-se este relativo desapontamento, pois, de facto, não há uma discussão detalhada dos sistemas de propriedade e muito menos das lógicas e relações de produção, o que até poderia ser bastante útil também para melhor entender as desigualdades. Por outro lado, não deixa de ser verdade que Piketty põe a nu um dos maiores pilares do capitalismo - $r>$ g enquanto força de reprodução cumulativa exacerbada do patrimônio - e propõe uma abordagem política para controlar o ritmo, os processos e a magnitude de aglomeração do capital, bem como, no limite, inviabilizar a eternização da sua posse. Se um dia a história nos contemplar com a concretização desta estratégia, esse momento poderá ser o início de um modo de organização econômico-financeira significativamente distinto daquilo a que hoje chamamos capitalismo.

Em jeito de balanço final, permito-me apontar aquilo que julgo serem três aspectos passíveis de apreciação menos positiva na obra e, em sentido contrário, as suas três principais virtudes. Considero menos positivo (i) a falta de explicação detalhada e convincente sobre o quadro de circunstâncias sociais que está na base do forte desequilíbrio entre o rendimento do capital e o crescimento da economia, tal como, de resto, é apontado por Harvey (2014) e Lobato (2014); (ii) a concepção restritiva e materialista da noção de capital, não tendo em conta que ele, mais do que uma coisa, é um processo (Harvey, 2014), nem considerando outras formas de capital (v.g. simbólico, social, cultural) determinantes, justamente, no processo de produção das assimetrias e distinções sociais (Bourdieu, 2007); (iii) a incapacidade em compreender as desigualdades também em função do ordenamento cultural de crenças que constitui o "espírito do capitalismo" ou seja, os elementos que o legitimam e sustentam as práticas e predisposições que lhe são compatíveis (Boltanski e Chiapello, 2007). Apesar dos senãos, este é, decididamente, um livro que merece ser lido. Comporta um trio de virtudes que destaco: (i) mostranos com grande densidade histórica e com particular detalhe empírico a capacidade de condensação do capital e os princípios estruturais que impulsionam a progressão das desigualdades; (ii) proporciona elementos para melhor entender e escassa utilidade social da grande acumulação patrimonial e, assim, contraria a perspectiva da teoria 
trickle-down, segundo a qual a riqueza de uma pequena minoria acaba por gerar vantagens significativas para todos; (iii) projeta possíveis escolhas políticas para a democracia regular efetivamente uma economia de mercado monopolizada por princípios utilitaristas, desenraizada de outras instituições sociais e dos seus respectivos preceitos e, não raro, em contramão da sociedade. Cabe aqui lembrar as provectas, mas atuais, reflexões de Polanyi (2012) e não esquecer a urgência de abrir esta economia fechada sobre si própria e reificada, conferir-lhe poética e política, e assegurar que seja reinserida (re-embeded) no terreno da vida social em prol da utilidade comum.

\section{Referências}

BOLTANSKI, L., E CHIAPELLO, È. (2007). The new spirit of capitalism. Londres e Nova Iorque: Verso.

BOURDIEU, P. (2007). A distinção: crítica social do julgamento. Porto Alegre: Zouk.

GALBRAITH, J. (2014). Kapital for the twenty-first century?, Dissent, 61 (2), 77-82.

HARVEY, D. (2014). Afterthoughts on Piketty's Capital. Disponível em http://davidharvey.org/ 2014/05/ afterthoughts-pikettys-capital/. Acesso em 12 de Março de 2015.

LOBATO, M. (2014). Reseña de "El Capital en el Siglo XXI", de Thomas Piketty. Periféria-Revista de Recerca I Formació en Antropologia, 19 (2), 144-156.

POLANYI, K. (2012). A grande transformação: as origens políticas e económicas do nosso tempo. Lisboa: Edições 70. 